\title{
Verifying the Frequency Ratios in the Musical Scale of Just Intonation with "Hear-and-See" Learning Tools
}

\begin{tabular}{|r|l|}
\hline Journal: & Computer Applications in Engineering Education \\
\hline Manuscript ID & Draft \\
\hline Wiley - Manuscript type: & Research Article \\
\hline Date Submitted by the Author: & n/a \\
\hline Complete List of Authors: & Pejuan, Arcadi; Universitat Politècnica de Catalunya, Physics \\
\hline Keywords: & $\begin{array}{l}\text { audio editor, Audacity, hear-and-see learning tools, musical scale, musical } \\
\text { intervals }\end{array}$ \\
\hline
\end{tabular}

This is the pre-peer reviewed version of the following article: A. Pejuan, Verifying the Frequency Ratios in the Musical Scale of Just Intonation With "Hear-and-See" Learning Tools, Comput Appl Eng Educ 25 (2017), 5-14, DOI 10.1002/cae.21771, which has been published in final form at http://onlinelibrary.wiley.com/doi/10.1002/cae.21771/full . 


\author{
Verifying the Frequency Ratios in the Musical Scale of Just Intonation with "Hear- \\ and-See" Learning Tools
}

\begin{abstract}
:
In engineering colleges, Acoustics often includes the musical scale topic, which is not very popular with most engineering students. In order to face this situation, this paper presents two alternative or complementary "hear-and-see" learning tools for the musical scale of just intonation. The first one combines the hearing of musical notes from an electric organ with the display on an oscilloscope from which the frequency ratios are inferred. Alternatively, the frequencies are computed in advance on the basis of the theoretical frequency ratios, and an audio editor allows to hear the resulting notes, while the PC screen can display similar graphs to those on the oscilloscope.
\end{abstract}

Keywords: audio editor, Audacity, hear-and-see learning tools, musical scale, musical intervals.

\title{
INTRODUCTION
}

In engineering colleges, Acoustics often includes Musical Acoustics. A significant part of it deals with the frequency ratios in the musical scales of the Western music. This especially includes the musical scale of just intonation, which was the historical base for the currently most used equi-tempered scale, with hardly perceptible pitch differences, so that the procedures described here are also valid to a very good approximation when using this current musical scale. 
This topic is not very popular with most engineering students. Therefore, this paper presents two alternative or complementary "hear-and-see" learning tools for dealing with this topic in a hands-on way. The first one combines the hearing of the musical scale notes with the display of graphs on an oscilloscope, from which the corresponding frequency ratios can be immediately inferred. With the second learning tool, the previous computing of frequencies is required, which can be carried out using a spreadsheet (e.g. Microsoft Excel). Then a plain audio editor allows to hear the resulting notes on the PC, in order to verify the frequency ratios of the musical intervals involved. In addition, the PC screen can display similar graphs to those on the oscilloscope. The same procedure could be applied to the equi-tempered scale using the corresponding frequency ratios, allowing musically trained ears to perceive the small pitch differences between both musical scales. Both procedures can be considered multimedia learning tools which help students to verify the aforementioned frequency ratios in a tangible way.

In the next section, the theory that underlies to the musical scale of just intonation is considered in order to specify the frequency ratios involved. A subsequent section presents the first arrangement using an oscilloscope and a plain electric organ. The section following thereafter describes the second alternative or complementary arrangement using a PC with an audio editor, including the previous computing of the involved frequencies in a spreadsheet. Finally, another section reports the increase in the students' learning performance with regard to the musical scale topic after implementing these "hear-andsee" learning tools. 


\section{THEORETICAL BASIS: FREQUENCY RATIOS IN THE MUSICAL SCALE OF JUST INTONATION}

Melodies and harmonies in all types of music use sounds or 'musical tones' of discrete pitches with given fundamental frequencies, which form musical scales. In all musical cultures of the world, these frequencies in a scale are interrelated by given frequency ratios, which differ in the different musical cultures. But there is a frequency ratio, that of 1:2 or $2: 1$ called 'octave', which is common to all musical cultures as a musical universal [1]. This was also the first permissible consonant (i.e. pleasant) tone combination already stated by the Pythagorean school in the $6^{\text {th }}$ century B.C. [2]. As experience has shown, even students with no musical training understand the concept of octave jumps between tones if it is introduced qualitatively (e.g. the difference between the voices of boys and girls singing the same melody together in octaves) and in fact, tones an octave apart share certain perceptual features and are often confused with one another, even by absolutepitch possessors [1]. In addition, listeners seem more sensitive to deviations from the octave than to deviations from adjacent intervals [3].

The musical scale of just intonation, especially used in the Western music until the $17^{\text {th }}$ century, has an arithmetical basis already established by the ancient Pythagorean school in the $6^{\text {th }}$ and $5^{\text {th }}$ century B.C., conveniently extended by Ptolemy (130 C.E.) and theorists and historians of later ages $[2,4,5]$. As is well known, the Pythagoreans saw the link between basic musical sounds and numbers. This was, for the Pythagoreans, a basic aspect of the harmony of the universe, which was expressed as numerical relationships as a part of the 'mysticism of numbers'. A paradigm of this is the relationship between three 
given lengths of the same tensed string that, when plucked, gave a 'major triad' chord (using today's musical language). For example, the chord formed by the musical notes $\mathrm{C}$, $\mathrm{E}$ and $\mathrm{G}$ constitutes the basic chord of the most well-known scale (or key) of C major. As the ancients like the Pythagoreans were, many today's students are captivated by the fact that these three consonant or 'harmoniously sounding' lengths correspond to a numerical relationship of 4:5:6, a 'mystical relationship' in the aforementioned sense. Incidentally, for the Pythagoreans, the numerical 1:2 relationship of an octave jump was even more significant than 4:5:6, since the numbers 1 and 2 are 'simpler' than 4, 5 and 6, and, accordingly, the octave chord is more consonant. (This 'mysticism of numbers' has a scientific explanation based on the psychophysical response of the human brain to the interference of the respective higher harmonics resulting in pleasant beats: see $[2,6-9]$.)

The recurring nature of this 'mystical relationship' is a point that further captivates interest. If the whole procedure is repeated starting from the note $G$ upwards, another basic major triad is obtained, the major triad of G, which is formed by the notes G, B and D. The process is described in Figure 1 (top left), in which use is made of the convention of identifying the octave by means of a subscript to the note concerned, where the octave number 4 is assigned to the octave containing the note A with a reference frequency of $440 \mathrm{~Hz}$, i.e. $\mathrm{A}_{4}$. This same convention applies to all of what follows in this paper.

[Insert Figure 1 about here] 
Finally, if the same procedure is repeated once more starting from the other end of the initial major triad of $\mathrm{C}$ (from $\mathrm{C}$ downwards), another major triad is found, formed by the notes $\mathrm{C}, \mathrm{A}$ and $\mathrm{F}$ (Figure 1).

With the three preceding triads, all of the notes that form the musical scale of just intonation are obtained when applying the appropriate octave jumps, as shown in Figure 1. Even students who have not had any musical training are aware of this scale: C, D, E, F, G, A, B, (C). Since the starting note (or keynote) is C, it is also referred to as 'key of C'.

There is a further interesting aspect of this frequency ratios. By transposition, these triads give rise to the three basic chords of any given key. Indeed, as most accordionists know, it is possible to accompany most popular melodies with just these three chords. To explain this point, we have to use the bass clef (Figure 2, staff nos. 2, 4 and 6). At the piano, this bass clef is usually used for the left hand, which is very often in charge of accompanying the melodies, which are in turn played with the right hand. Figure 2 shows several ways of writing the three basic chords seen in Figure 1. Figure 3 shows two examples of how a significant proportion of all popular melodies may be accompanied using only these three basic chords.

[Insert Figure 2 about here]

[Insert Figure 3 about here]

\author{
VERIFYING THE FREQUENCY RATIOS OF THE SCALE OF JUST \\ INTONATION USING AN OSCILLOSCOPE
}

John Wiley \& Sons 
How can the different frequency ratios be observed in the physics laboratory in a way which is directly tangible for the student? A first adequate arrangement is shown in Figure 4 as a suitable "hear-and-see" learning tool - a simple electric organ is provided with a direct connection to its loudspeaker, from which the signal for an oscilloscope is taken. Usually, a simple electric organ does not provide the possibility of choosing a temperament of just intonation, but the frequency differences between the usual equitempered intonation and the just intonation are so small, that they are negligible in the oscilloscope display. An organ sound giving a wave shape as close as possible to a sinusoidal one should be chosen. Often, the organ sound designated as 'Flute' is the most appropriate. If possible, it is advisable to suppress any vibrato or similar effect (tremolo, chorus, etc.), in order to obtain frequencies which are as pure as possible.

To display the octave frequency ratio 1:2 (for the first octave, and equivalently, 2:4 for the next octave), the time base of the oscilloscope (marked 'Time/Div.') must be adjusted by sight so that, when playing e.g. a $\mathrm{C}_{3}$ on the organ, exactly one full oscillation appears on the screen (figure $4,{ }^{\prime} \mathrm{C}_{3}$ '). Now, without readjusting the oscilloscope, the octave note of $\mathrm{C}_{3}$, i.e. $\mathrm{C}_{4}$, is played, and the oscilloscope screen shows 2 full oscillations on the screen (figure $4,{ }^{\prime} \mathrm{C}_{4}$ '). This procedure can be repeated with the next octave note, $\mathrm{C}_{5}$, observing 4 full oscillations on the screen (figure $4,{ }^{~ '} \mathrm{C}_{5}$ '). Since the screen sweep time is constant in all three cases, the respective frequencies are related in a ratio of 1:2:4, i.e. each octave is related to the next one in a ratio of 1:2. 
[Insert Figure 4 about here]

To display the frequency ratios in a major triad, e.g. that of $\mathrm{C}$, the time base of the oscilloscope must now be adjusted so that, when playing a $\mathrm{C}$ on the organ, exactly 4 full oscillations appear on the screen (Figure 5, 'C'). Also without readjusting the oscilloscope in the following, the next note of the $\mathrm{C}$ major triad, i.e. the $\mathrm{E}$, is played, and the oscilloscope screen shows 5 full oscillations (Figure 5, 'E'). Repeating this exercise with the next note of the $\mathrm{C}$ major triad, i.e. the $\mathrm{G}, 6$ oscillations are observed on the screen (Figure 5, 'G'). Since the screen sweep time is constant in all these three cases, the respective frequencies are indeed related in a ratio of $4: 5: 6$.

[Insert Figure 5 about here]

Now, if the time base in the oscilloscope is adjusted again, so that exactly four full oscillations are displayed for the note $\mathrm{G}$, and then the notes B and D are played, we find the same 4:5:6 relationship between the frequencies of these three notes, $\mathrm{G}, \mathrm{B}$ and $\mathrm{D}$, as described in the preceding section (Figure 1, top left).

To display the third major triad considered in the preceding section, the time base has to be adjusted so that exactly six full oscillations are displayed when the initial $\mathrm{C}$ is played. Then, if the notes A and F are played (downwards), the oscilloscope screen reveals the same 4:5:6 relationship for this new major triad of $F(F, A$ and $C)$. 
In this way, the recurrent frequency ratio of 4:5:6 between the basic triads of notes that give rise to the musical scale of just intonation can be verified, combining sound with oscilloscope display.

\section{VERIFYING THE SAME FREQUENCY RATIOS USING A PC WITH AN AUDIO EDITOR}

The preceding learning tool with oscilloscope and electric organ certainly has its benefits, such as promoting the skill in using the oscilloscope and interpreting its display, in addition to flexibility and hands-on immediacy. However, there is an alternative or complementary "hear-and-see" learning tool with means which are more easily available, especially in the classroom - just a PC equipped with a simple audio editor such as Audacity (a free software application from SourceForge.net, https://sourceforge.net/projects/audacity) and a spreadsheet such as Microsoft Excel. The good features of Audacity have been described and compared to those of other audio editing software by [10]. In general, these other audio editors are more powerful for specific purposes, but Audacity is available online for free and its features are completely sufficient for our purposes. The Microsoft Excel spreadsheet has proven to be useful as a tool for teaching different topics to undergraduate engineering students $[11,12]$.

This alternative or complementary procedure works in reverse order to that of the preceding section. Instead of first producing the musical notes and then checking the 
frequency ratios, now the frequencies are calculated from the theoretical frequency ratios and then the resulting musical results are checked out.

The same procedure could be applied for computing the frequency ratios for the equi-tempered scale. This would additionally allow musically trained ears to perceive the very small pitch differences between both musical scales.

\section{Computing the Frequencies Involved in the Diatonic Major Triads}

So, the first step is that students autonomously systematize the arithmetical procedure described in section "Theoretical Basis..." by means of a spreadsheet, in order to obtain the frequencies in the three basic major triads of the key of C, namely C-E-G, G-B-D, and F-A-C.

The resulting spreadsheet could look like that in Figure 6, where also the computation formulae are specified. For comparison purposes, all frequency ratios (column $\mathrm{H}$ ) are referred to the frequency of the note $\mathrm{C}_{4}$. From these frequency ratios, each frequency is computed in column $\mathrm{J}$, based on the usual reference frequency of $440 \mathrm{~Hz}$ for the note $\mathrm{A}_{4}$. (Of course, this results in a frequency of $220 \mathrm{~Hz}$ for $\mathrm{A}_{3}$, an octave lower)

[Insert Figure 6 about here] 
Just as a supplementary exercise, all the frequencies of the diatonic scale of C major in just intonation can be computed as in the spreadsheet of Figure 7, using the frequency ratio of 1:2 for the appropriate octave jumps (in agreement with Figure 1).

[Insert Figure 7 about here]

\section{Programming and Hearing the Resulting Musical Notes and Chords}

The second step of this procedure is to generate the musical sounds which have the frequencies computed in the previous step, in order to perceive, by hearing, that they indeed make up the major triads considered.

As a preparation, the frequency ratio 1:2 for any octave interval should be verified, as in the preceding section with the oscilloscope. The following procedure can be used both for the octave and the major triads.

If the aforementioned audio editor Audacity is used, the single musical notes involved e.g. in any octave interval can be generated and heard as follows:

- Open the audio editor in your PC.

- In the upper menu bar, select "Generate > Tone...", opening the pop-up window "Tone Generator". If necessary, select the settings "Wave form: Sine", "Amplitude 0.8 " and "Duration: 000,002 seconds" (or any other duration if preferred).

- Enter the frequency of the note to be heard, i.e. any frequency for the octave jump, for example $123 \mathrm{~Hz}$. For identification purposes, a suitable track name can be 
given, e.g. "123Hz", through the "Audio Track" pull-down menu.

- Repeat the procedure with the a double frequency value, in our example $246 \mathrm{~Hz}$ (a first octave jump), and a fourfold frequency, in our example $492 \mathrm{~Hz}$ (a further octave jump). Each time the option "Generate $>$ Tone" is selected, it is important to check that a new blank for this new tone is displayed. Otherwise, the new track would overwrite the existing one. This will occur if the existing track was selected. In such a case, cancel the generation of the new tone and make sure that the existing track is deselected, before repeating the procedure. Figure 8 shows the upper left-hand area of the resulting screen.

[Insert Figure 8 about here]

- Now the different tones with the selected frequencies can be heard either each after the other or two of them or all three simultaneously. For the former, click on the Mute buttons of the notes that are not to be played yet (Figure 9, black arrows). Then click on the play button (black square mark), and the tone will be played. By switching the Mute buttons, the other single notes can be heard, as well as any combination of them. In this way, it can be verified, by hearing, that these tones are separated by octave intervals.

[Insert Figure 9 about here] 
The same procedure is used for the major triads, using the computation in the previous subsection (Figure 6). For example, taking $\mathrm{C}_{4}$ as starting note of the first major triad, generate tones of $264 \mathrm{~Hz}$ (for $\mathrm{C}_{4}$ ), $330 \mathrm{~Hz}$ for $\mathrm{E}_{4}$, and $396 \mathrm{~Hz}$ for $\mathrm{G}_{4}$. The resulting display is shown in part in Figure 10, where the different audio tracks have been labeled "C4 - 264Hz", etc. for convenience. Again, the different resulting tones can be heard either each after the other or two of them or all three simultaneously, by switching the Mute buttons. This procedure can now be repeated again for the other major triads.

[Insert Figure 10 about here]

In this way, it can be verified, by hearing, that the notes obtained from the theoretical frequency ratios of section "Theoretical Basis..." do form the major triads of the musical scale of just intonation, including any octave jump.

This arrangement with an audio editor can reproduce the display obtained in the preceding section with the oscilloscope (Figures 4 and 5), in order to visually confirm the respective frequency ratios involved. Following procedure can be used either with the octave jumps (Figure 8) or the major triads (Figure 10):

- With the mouse, select a small portion of any of the tracks, from right to left until the track beginning (e.g. from about $0.03 \mathrm{~s}$ until $0 \mathrm{~s}$ in the upper time scale).

- Select "View $>$ Zoom to selection" in the upper menu bar. Now, the selected portion of track fits the whole screen and the single periods are now clearly visible.

- For the octave intervals, select just one period with the mouse, and again select 
"View > Zoom to selection" in the upper menu bar. Figure 11 shows the result, which has the same interpretation as Figure 4 obtained with the oscilloscope.

[Insert Figure 11 about here]

- For the major triads, starting e.g. with the $\mathrm{C}_{4}$ major triad on the screen (Figure 8), repeat the procedure, but now selecting four periods instead of one. The result is as in Figure 12, which matches Figure 5 obtained with the oscilloscope.

[Insert Figure 12 about here]

A similar procedure could be applied for computing the frequency ratios and generating the corresponding tones for the equi-tempered scale.

\section{STUDENTS' RESPONSE}

These learning tools were implemented within the framework of an elective course on Acoustics, but only after four semesters of delivering it at our engineering school, so that in the first four semesters, these learning tools were not used at all. Meanwhile, the first arrangement (with oscilloscope) has been used for five semesters, while the second learning tool (audio editor) has been additionally or alternatively used for the last three semesters of this second period of five semesters. 
Since the beginning, the final exam has included a question or short problem on the musical scale as one of the topics of the course syllabus, although it was not the most important topic. Accordingly, its proportion within the exam mark has been 1 point out of 10. The mean mark and its $95 \%$ confidence interval for the questions or short problems on the musical scale was $0.26 \pm 0.03$ (out of 1 ) in the period before implementation of these learning tools ( $n=102$ students) and, in contrast, $0.51 \pm 0.05$ in the period after implementation ( $n=117$ students). No significant mean mark difference could be observed when using the first learning tool (with oscilloscope), the second one, or both of them.

Both of these mean marks are not specially outstanding and, indeed, the musical scale is not a priority topic for most engineering students. However, there is a significant increase in the mean mark after implementation of these learning tools, while the other course features remained virtually unaltered with regard to the musical scale topic.

\section{CONCLUSIONS}

The first "hear-and-see" learning tool described is a hands-on procedure with an oscilloscope and a simple electric organ, combining the hearing of the different musical scale notes with the display of graphs from which the corresponding frequency ratios can be immediately inferred. In this way, it is possible to directly verify the frequency ratios between notes already established in the antiquity by the Pythagorean school and Ptolemy for the musical scale of just intonation, which was the base for the currently used equitempered scale, with hardly perceptible pitch differences. 
An alternative or complementary learning tool is available in the form of a simple audio editor like Audacity in combination with a spreadsheet like Microsoft Excel. This arrangement allows to generate the tones of the musical scale after computing the corresponding frequencies on the basis of the theoretical frequency ratios. In this way, it is also possible to verify, by hearing, that these frequency ratios lead to the different notes of the musical scale. In addition, this software learning tool allows to verify the frequency ratios visually on the PC screen in a similar way to the oscilloscope.

The implementation of these learning tools has led to a significant increase in the students' learning performance concerning the musical scale topic, even if this topic is not very popular with most engineering students. 


\section{REFERENCES}

[1] D. J. Levitin and S. E. Rogers, Absolute pitch: perception, coding, and controversies, Trends Cogn. Sci., 9 (2005), 26-33.

[2] D. L. Bowling and D. Purves, A biological rationale for musical consonance, PNAS 112 (2015), 11155-11160.

[3] J. H. McDermott and A. J. Oxenham, Music perception, pitch, and the auditory system, Cur Op Neur 18 (2008), 452-463.

[4] R. L. Crocker, Pythagorean Mathematics and Music, J Aesthet Art Crit 22 (1963), 189-198.

[5] J. Godwin, The Harmony of the Spheres: The Pythagorean Tradition in Music. Inner Traditions/Bear \& Co., Rochester (Vermont), 1992.

[6] H. L. Helmholtz and A. J. Ellis, On the Sensations of Tone as a Physiological Basis for the Theory of Music, Cambridge University Press, 2009.

[7] Y. I. Fishman, I. O. Volkov, M. D. Noh, P. C. Garell, H. Bakken, J. C. Arezzo, M. A. Howard, and M. Steinschneider, Consonance and Dissonance of Musical Chords: Neural Correlates in Auditory Cortex of Monkeys and Humans. J Neurophys 86 (2001), 2761-2788.

[8] G. M. Bidelman and A. Krishnan, Neural Correlates of Consonance, Dissonance, and the Hierarchy of Musical Pitch in the Human Brainstem. J Neurosci 29 (2009), 13165-13171. 
[9] O. Bones and C. J. Plack, Losing the Music: Aging Affects the Perception and Subcortical Neural Representation of Musical Harmony. J Neurosci 35 (2015), $4071-4080$.

[10] A. Pejuan, X. Bohigas, X. Jaén, and C. Periago, Comparative study of three audio processors as environments for laboratory activities on wave physics and acoustics, Comput Appl Eng Educ 21 (2013), E89-E99.

[11] I. S. Qamber and M. R. Qader, Development and Evaluation of Laboratory Tool Applied to Electric Power Radial System, Comput Appl Eng Educ 17 (2009), 479483.

[12] A. Rivas, T. Gomez-Acebo, and J. C. Ramos, The application of spreadsheets to the analysis and optimization of systems and processes in the teaching of hydraulic and thermal engineering, Comput Appl Eng Educ 14 (2006), 256-268. 
Figure 1 Obtention of both the other basic major triads starting from the $\mathrm{C}$ major triad (broad arrows), and obtention of the notes of the diatonic major scale of just intonation from the three basic major triads (in each circle, the number of octave jumps is shown). [Color figure can be viewed in the online issue, which is available at wileyonlinelibrary.com]. $645 \times 125 \mathrm{~mm}$ (96 x 96 DPI) 




Figure 2: Obtaining the basic chords for the accompaniment of melodies, starting from the major triads, by means of octave jumps. [Color figure can be viewed in the online issue, which is available at wileyonlinelibrary.com].

$392 \times 365 \mathrm{~mm}(96 \times 96 \mathrm{DPI})$ 

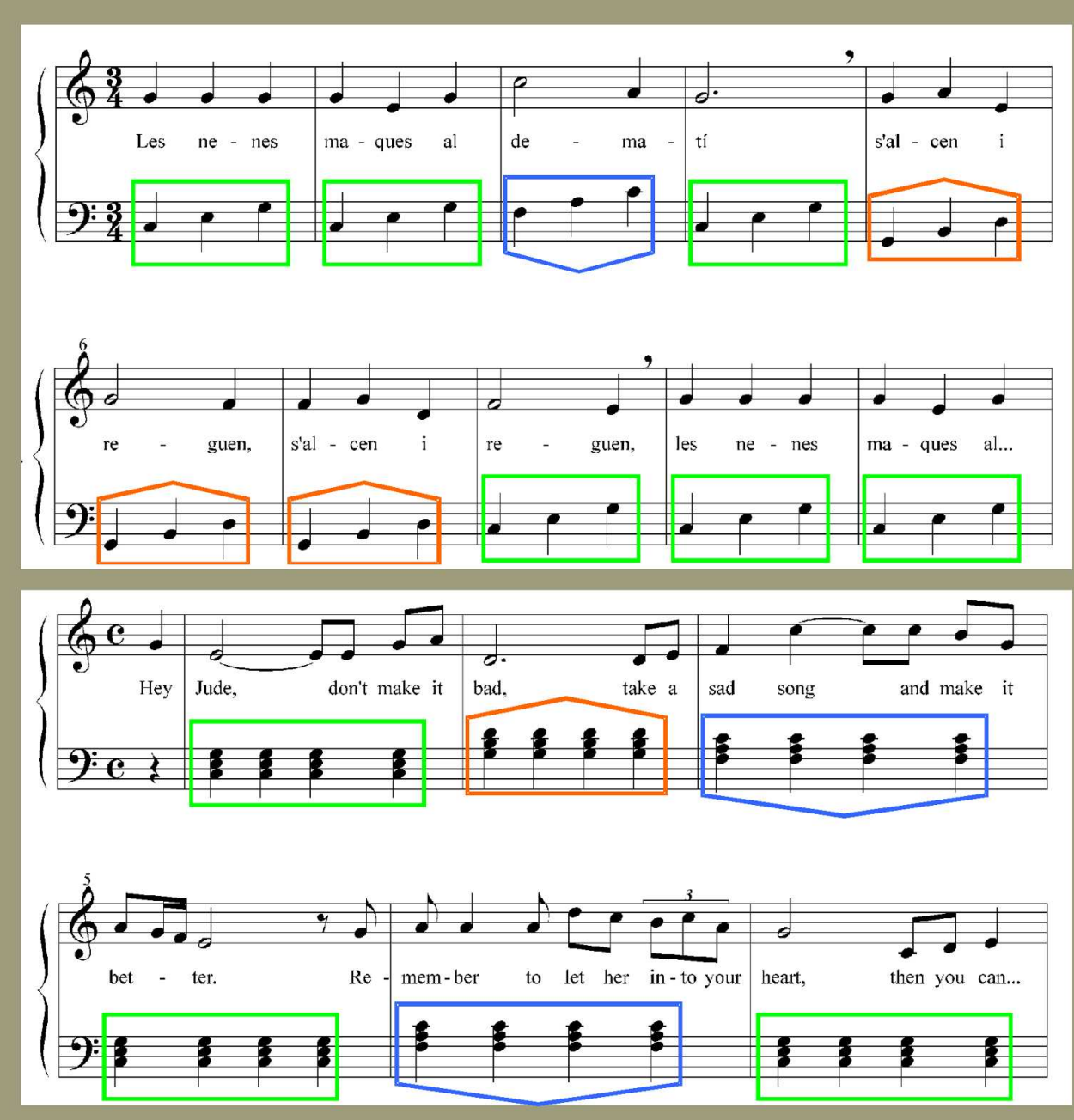

Figure 3: Example illustrating the practical significance of the three basic major triads: simple accompaniments for two popular songs (the second one is by J. Lennon and P. McCartney, although the original accompaniment is, of course, more elaborate), based on the major triads alone. [Color figure can be viewed in the online issue, which is available at wileyonlinelibrary.com]. 
Figure 4: Display of the 1:2 relationship between the notes of every octave interval by means of the oscilloscope. [Color figure can be viewed in the online issue, which is available at wileyonlinelibrary.com]. $510 \times 960 \mathrm{~mm}(78 \times 78 \mathrm{DPI})$ 

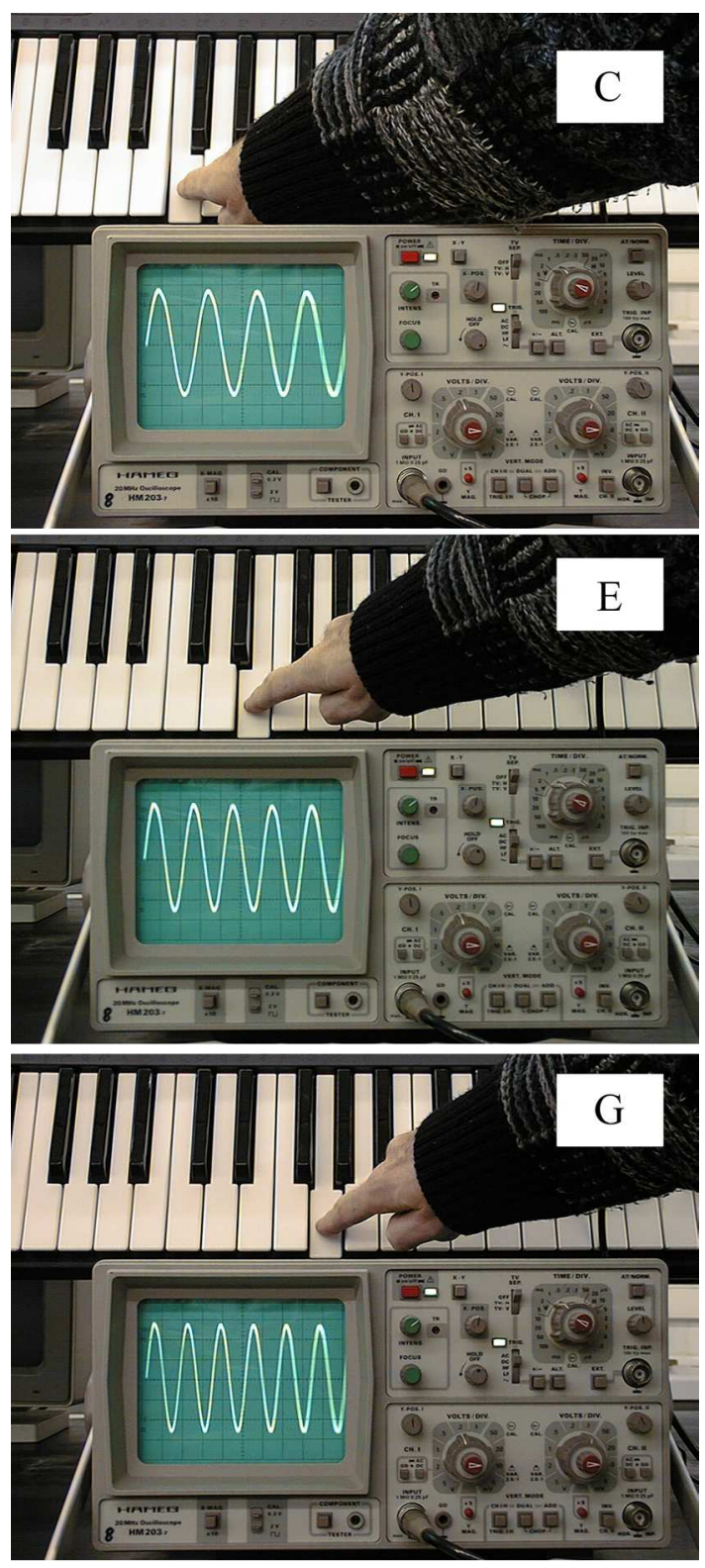

Figure 5: Display of the 4:5:6 relationship between the notes of a major triad (here the $C$ major triad) by means of the oscilloscope. [Color figure can be viewed in the online issue, which is available at wileyonlinelibrary.com]. $84 \times 190 \mathrm{~mm}(300 \times 300 \mathrm{DPI})$ 


\begin{tabular}{|c|c|c|c|c|c|c|c|}
\hline $\bar{A}$ & $\mathrm{~B}$ & $\mathrm{C}$. & $E$ & $F$ & $G$ & $\mathrm{H}$ & $J$ \\
\hline & & & & & & $f / f_{\mathrm{C} 4}$ & $f(\mathrm{~Hz})$ \\
\hline$C_{4}$ & 4 & 4 & $x$ & 1.0000 & $=$ & 1.0000 & 264.00 \\
\hline$E_{4}$ & 5 & 4 & $x$ & 1.0000 & $=$ & 1.2500 & 330.00 \\
\hline \multirow[t]{2}{*}{$\mathrm{G}_{4}$} & 6 & 4 & $x$ & 1.0000 & $=$ & 1.5000 & 396.00 \\
\hline & & & & $\checkmark$ & & J & \\
\hline $\mathrm{G}_{4}$ & 4 & 4 & $x$ & 1.5000 & $=$ & 1.5000 & 396.00 \\
\hline$B_{4}$ & 5 & 4 & $x$ & 1.5000 & $=$ & 1.8750 & 495.00 \\
\hline$D_{5}$ & 6 & 4 & $x$ & 1.5000 & $=$ & 2.2500 & 594.00 \\
\hline$F_{3}$ & 4 & 6 & $x$ & 1.0000 & $=$ & 0.6667 & 176.00 \\
\hline$A_{3}$ & 5 & 6 & $x$ & 1.0000 & $=$ & 0.8333 & 220.00 \\
\hline $\mathrm{C}_{4}$ & 6 & 6 & $x$ & 1.0000 & $=$ & 1.0000 & 264.00 \\
\hline & & & & & & & \\
\hline
\end{tabular}

\section{Comments and Formulae in Excel language:}

$B: D=$ frequency ratios in each major triad.

$F=B / D=$ frequency ratio of the starting note in the major triad with regard to $\mathrm{C}_{4}$.

$\mathrm{H}=\mathrm{B} / \mathrm{D}^{*} \mathrm{~F}=$ frequency ratio of each note to $\mathrm{C}_{4}$.

$\mathrm{J}=\mathrm{H} /(5 / 3) * 440=$ frequency $($ in $\mathrm{Hz}$ ) of each note, taking $440 \mathrm{~Hz}$ for $\mathrm{A}_{4}$.

Figure 6: Example of spreadsheet for calculating the frequency of every note in the major triads of the key of $\mathrm{C}$, based on the usual reference frequency of $440 \mathrm{~Hz}$ for the note $\mathrm{A}_{4}$. [Color figure can be viewed in the online issue, which is available at wileyonlinelibrary.com].

$94 \times 124 \mathrm{~mm}(200 \times 200 \mathrm{DPI})$ 


\begin{tabular}{|c|c|c|c|c|c|}
\hline A & B & C & D & $E$ & $F$ \\
\hline & $f / f_{\mathrm{C} 4}$ & 4th octave & & $f / f_{\mathrm{C} 4}$ & $f(\mathrm{~Hz})$ \\
\hline $\mathrm{C}_{4}$ & 1.0000 & $\Longrightarrow$ & $\mathrm{C}_{4}$ & 1.0000 & 264.00 \\
\hline$D_{5}$ & 2.2500 & ㄷ & $D_{4}$ & 1.1250 & 297.00 \\
\hline$E_{4}$ & 1.2500 & ᄃ & $E_{4}$ & 1.2500 & 330.00 \\
\hline$F_{3}$ & 0.6667 & $\Longrightarrow$ & $F_{4}$ & 1.3333 & 352.00 \\
\hline$G_{4}$ & 1.5000 & E & $\mathrm{G}_{4}$ & 1.5000 & 396.00 \\
\hline$A_{3}$ & 0.8333 & $\Longrightarrow$ & $A_{4}$ & 1.6667 & 440.00 \\
\hline$B_{4}$ & 1.8750 & $\Longrightarrow$ & $\mathrm{B}_{4}$ & 1.8750 & 495.00 \\
\hline
\end{tabular}

$$
\begin{aligned}
& \text { Comments and Formulae in Excel language: } \\
& \begin{aligned}
A & =\text { notes of the major triads } \\
B & =\text { frequency ratios in each major triad. } \\
D & =\text { notes of the } 4 \text { th pitch's octave. } \\
E & =I F(B>2 ; B / 2 ; I F(B<1 ; B * 2 ; B))= \\
& =\text { frequency ratio of each note to } C_{4} . \\
J & =E /(5 / 3) * 440=\text { frequency (in } \mathrm{Hz} \text { ) of each } \\
& \text { note, taking } 440 \mathrm{~Hz} \text { for } A_{4} .
\end{aligned}
\end{aligned}
$$

Figure 7: Example of spreadsheet for calculating the frequencies in the diatonic scale of $\mathrm{C}$ major in just intonation. [Color figure can be viewed in the online issue, which is available at wileyonlinelibrary.com].

$$
97 \times 102 \mathrm{~mm} \text { (200 x } 200 \text { DPI) }
$$




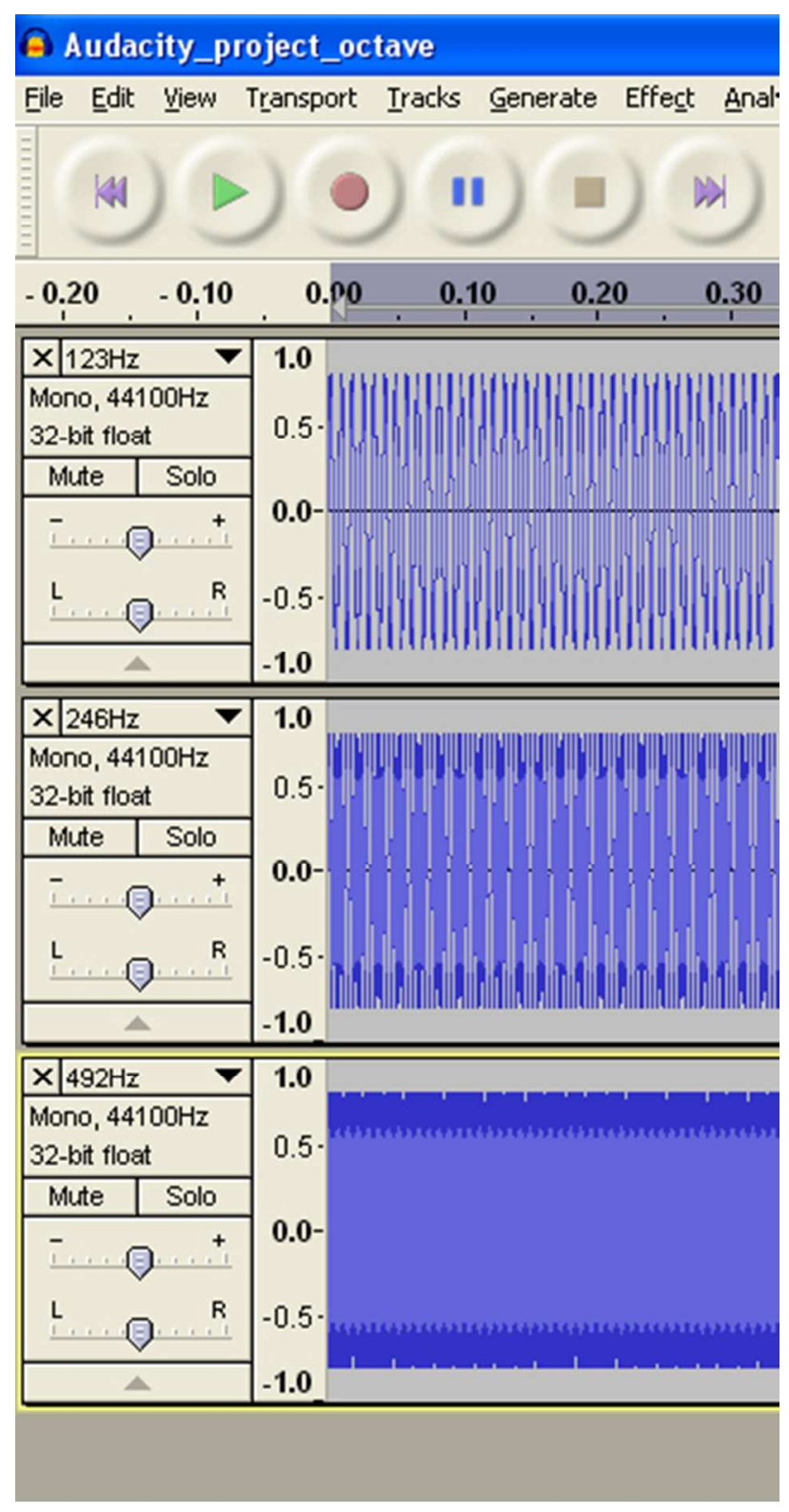

Figure 8: Upper left-hand area of the Audacity screen after generating three tones with octave jumps. [Color figure can be viewed in the online issue, which is available at wileyonlinelibrary.com]. $112 \times 218 \mathrm{~mm}(72 \times 72 \mathrm{DPI})$ 


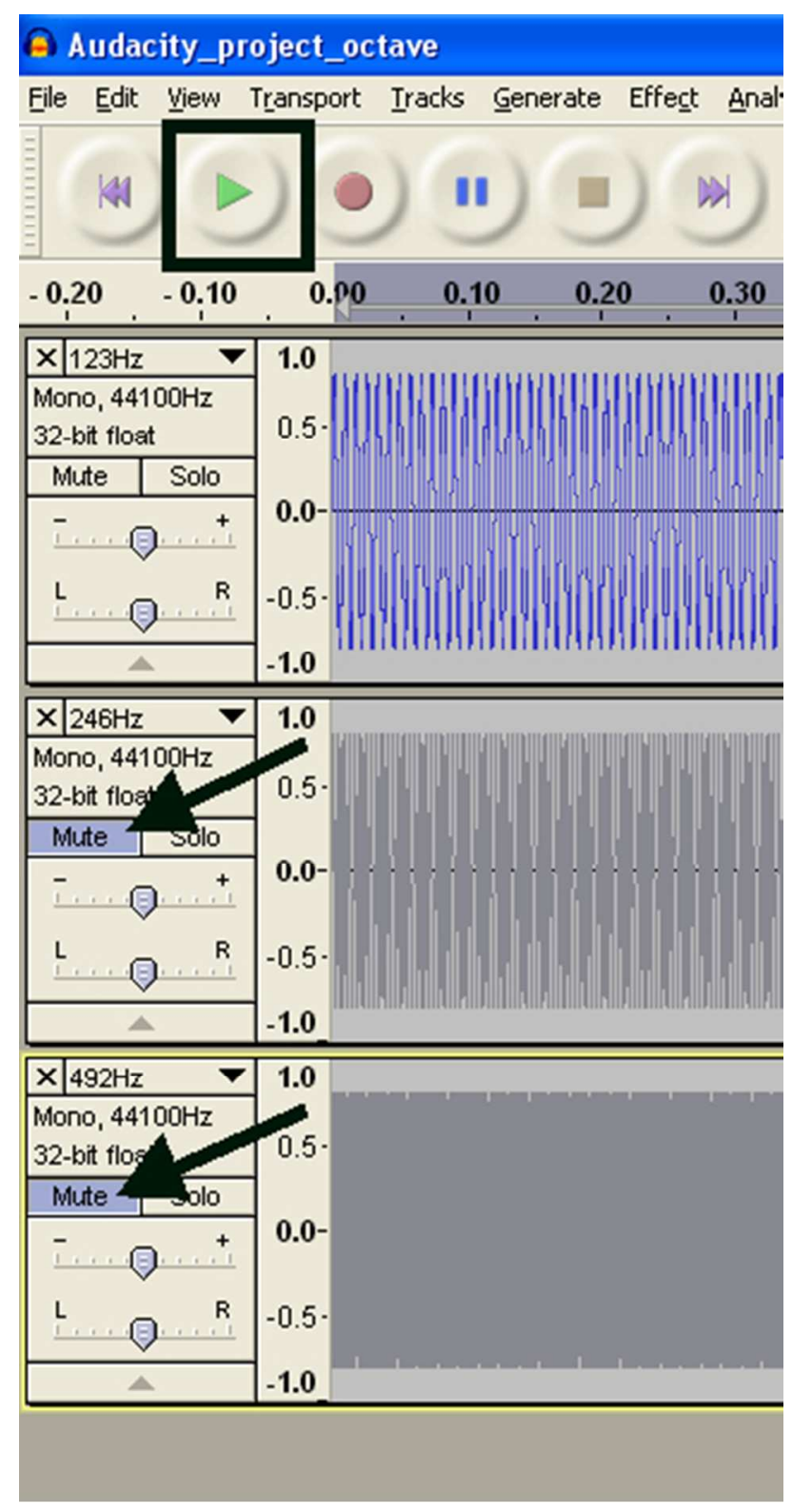

Figure 9: Selecting the track or tracks to be played, switching the Mute buttons, in order to verify by hearing that the tones generated are separated by octave intervals. [Color figure can be viewed in the online issue, which is available at wileyonlinelibrary.com].

$112 \times 218 \mathrm{~mm}(72 \times 72 \mathrm{DPI})$ 


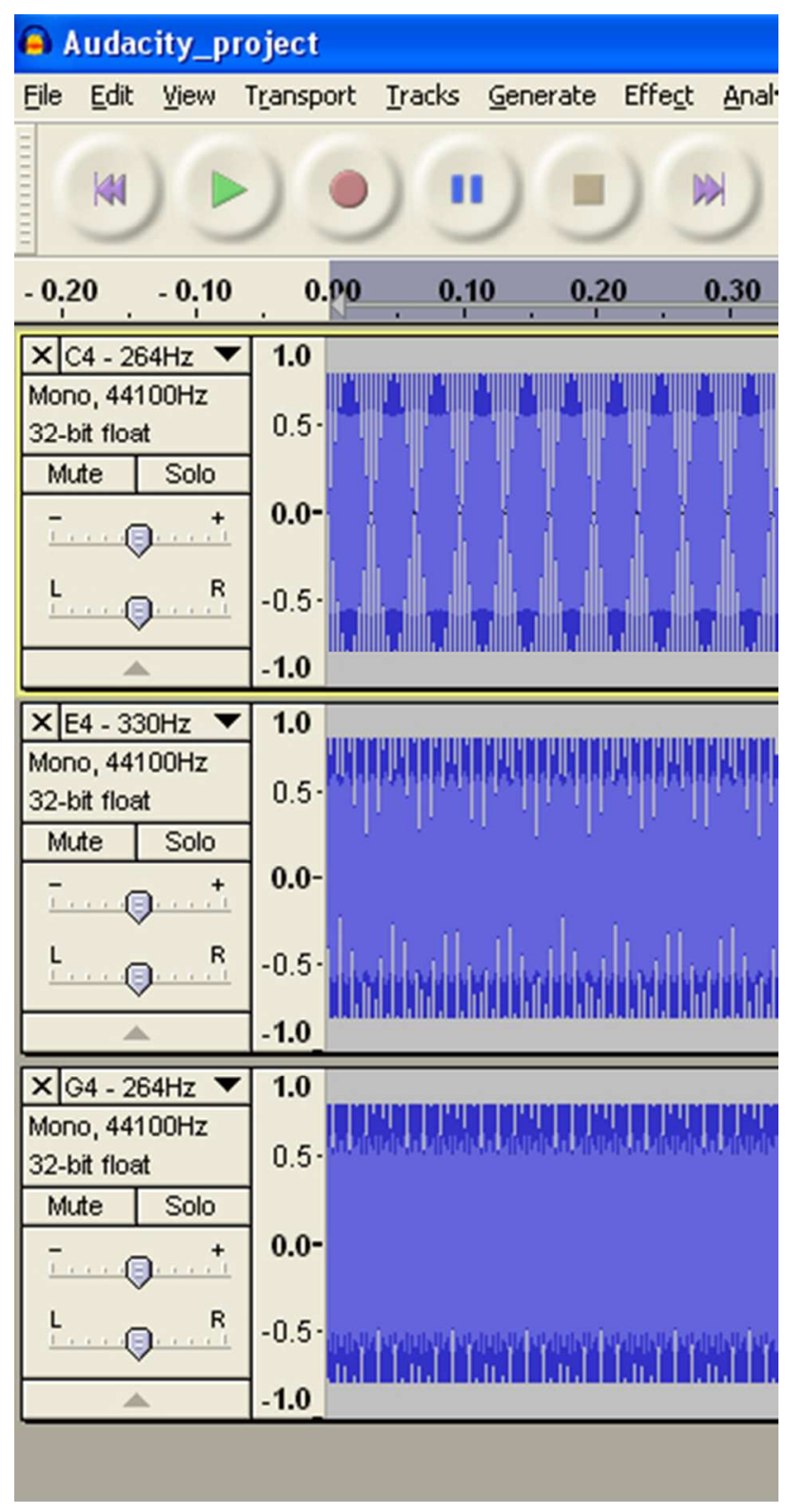

Figure 10: Upper left-hand area of the Audacity screen after generating all three tones of the $\mathrm{C}$ major triad. [Color figure can be viewed in the online issue, which is available at wileyonlinelibrary.com].

$$
112 \times 218 \mathrm{~mm}(72 \times 72 \text { DPI })
$$


Figure 11: Display obtained with Audacity for octave jumps, corresponding to the oscilloscope displays in Figure 4. [Color figure can be viewed in the online issue, which is available at wileyonlinelibrary.com]. $446 \times 169 \mathrm{~mm}(72 \times 72$ DPI $)$ 




Figure 12: Display obtained with Audacity for major triads, corresponding to the oscilloscope displays in Figure 5. [Color figure can be viewed in the online issue, which is available at wileyonlinelibrary.com]. $446 \times 169 \mathrm{~mm}(72 \times 72$ DPI) 